\title{
Older patients are more likely to breach the four-hour target in Scotland
}

Jonathan Quinn ${ }^{1}$, Scott Buchanan ${ }^{2}$, Phyo K Myint ${ }^{1,3}$, Graham Ellis ${ }^{4,5}$ : On behalf of Scottish Care of Older People National Audit Programme

1. Ageing Clinical \& Experimental Research Team, Institute of Applied Health Sciences, University of Aberdeen, Aberdeen, Scotland

2. NHS National Services Scotland, Information Services Division, Healthcare Improvement Scotland

3. Department of Medicine for the Elderly, NHS Grampian, Aberdeen, Scotland

4. NHS Lanarkshire, Scotland

5. Glasgow Caledonian University, School of Health and Life Sciences, Glasgow, Scotland

Mr Jonathan Quinn

Research Affiliate

Mr Scott Buchanan

Principal Information Analyst

Professor Phyo K Myint

Professor of Medicine of Old Age

Professor Graham Ellis

Consultant Physician

\section{Correspondence to:}

Professor Graham Ellis

National Clinical Lead for Older People, Scotland

Glendoe Building, Coathill Hospital,

Hospital Street, Coatbridge, ML5 4DN

Scotland

Tel: 01236712759

Mail to: g.ellis@nhs.net

Keywords: Emergency Care, Elderly

Word Count: 1,447 


\section{Older patients are more likely to breach the four-hour target in Scotland}

Abstract

57

Objective: To determine if age is a factor in a patients' likelihood of breaching the 4-hour time target to admission/discharge in Emergency Departments (EDs) within NHS Scotland.

60

Methods: We used data from the Information Service Division Scotland to analyse all ED attendances in Scotland between January 2015 and September $2018(n=5,596,642)$. We assessed the likelihood of time to admission/discharge being within 4 hours, 8 hours and 12 hours for all age categories (reference category 20-24 years). Univariable logistic regressions were carried out for sex, Scottish Index of Multiple Deprivation level and both major (potentially life threatening) and minor (not immediately life threatening) incidences.

Results: The likelihood of breaching the four-hour target increased linearly with age from $15-19$ years upward. Patients $\geq 85$ years were significantly $(\mathrm{p}<0.001)$ more likely to have breached than patients aged 20-24 years (Odds Ratio 3.80, 95\% Confidence Interval: 3.733.86). When considering major incidents, patients aged $\geq 85$ years were more likely to have breached than those aged 20-24 years (Odds ratio 2.05, 95\% Confidence Interval: 2.01-2.09, $\mathrm{p}<0.001$ ). The same was true of minor incidents (Odds Ratio 2.85, 95\% Confidence Interval: 2.73-2.98, $\mathrm{p}<0.001)$.

Conclusions: Older age is associated with a higher probability of breaching waiting time targets in a linear fashion within NHS Scotland, which is consistent with previous single hospital or regional studies. This association may be due to the higher proportion of elderly patients being admitted or a more systemic issue, but regardless, the elderly are being put more at risk.

What is already known on this subject:

- Previous studies have shown longer Emergency Department waits are associated with poorer patient outcomes.

- Previous studies have come to differing conclusions of the effects of age on emergency department waiting times.

- Previous studies have covered either single hospitals or regions.

What this study adds:

- In this study covering all hospitals in Scotland, over 5.5 million Emergency Department attendances were analysed.

- Our study shows that age is associated with longer waits in Emergency Departments to admission or discharge. This has implications for the configuration of our hospitals in relation to the ageing population. 


\section{Background}

85

The ageing population brings increased complexity of patient presentation to Emergency Departments (EDs), with greater comorbidities, frailty and increasing use of acute services: $65 \%$ of hospital beds in England are filled with adults over 65 [1] and $75 \%$ of delayed transfers from acute care, to a stepdown level of care or to the patient's home, are attributed to adults over 75 [2].

The ED waiting time (otherwise known as length of stay) from arrival to admission/discharge target is used as a whole system barometer of performance for hospital care. Longer ED stays are associated with patient dissatisfaction [3] and poorer patient outcomes, [4] [5] including increased mortality [6].

The NHS target states that $95 \%$ of all ED attendees should be admitted, transferred or discharged within four hours [7]. Within NHS Scotland, only 53 months (40\%) of 131 months between July 2007 and May 2018 met the 95\% 4-hour target in EDs [8].

Ideally, mature healthcare systems should be configured to meet the needs of their population, without age bias. Therefore, we should expect that ability of hospitals to meet the four-hour target would not differ by age.

\section{Methods}

We retrospectively analysed anonymised data extracted from the Information Service Division (ISD) Scotland, covering all ED attendances from across Scotland between January 2015 and September $2018(n=5,596,642)$. These data includes breaching percentage for 4, 8 and 12 hour waiting times and for major (potentially life threatening) or minor (not immediately life threatening) attendances, split by age into 5 year categories (and an $85+$ category). The percentage of patients in each age group that were admitted was also analysed, however individual level data was not available, thus multivariable analyses could not be performed.

Gender and Scottish Index of Multiple Deprivation (SIMD) were also recorded, but not split by age. SIMD 1 indicates a patient is from a more deprived area, up to SIMD 5 which is the least deprived. SIMD from 2016 was used and was calculated based on the patient's postcode. SIMD data were not recorded in 46,416 (0.83\%) attendances.

Using the age group 20-24 years as the reference category, we assessed the likelihood of time to admission/discharge exceeding 4, 8 and 12 hours for all age categories. Data were stratified by age for overall, major incident and minor incident time to admission/discharge, and also by gender \& SIMD category. Univariable logistic regression models were constructed to calculate odds ratios (ORs) and 95\% confidence intervals (CIs), with breaching the 4-hour target as the outcome and age, gender and SIMD category as predictor variables. Statistical significance was assumed if $\mathrm{p}<0.05$.

\section{Results}

The total number of attendances was 5,596,642, of which $51.1 \%$ were male. The median age of attendances was 36.8 years. Overall $8.03 \%$ of attendances breached the 4-hour target

133 (Table 1). 


\begin{tabular}{|l|c|c|}
\hline Characteristic & $\begin{array}{c}\text { Number of } \\
\text { Attendances }\end{array}$ & $\begin{array}{c}\text { Percentage } \\
\text { Breaching } \\
\text { 4 Hour Target Time }\end{array}$ \\
\hline Age (Median, IQR) & $38.6(42.0)$ & $8.03 \%$ \\
\hline Gender & $2,860,212$ & $7.57 \%$ \\
\hline Male & $2,736,430$ & $8.50 \%$ \\
\hline Female & $2,584,076$ & $13.84 \%$ \\
\hline Majors/Minors & $3,012,566$ & $2.13 \%$ \\
\hline Majors & $1,585,758$ & $8.49 \%$ \\
\hline Minors & $1,264,478$ & $7.86 \%$ \\
\hline SIMD Code & $1,004,983$ & $7.06 \%$ \\
\hline SIMD 1 & 882,127 & $6.63 \%$ \\
\hline SIMD 2 & 812,880 & $6.80 \%$ \\
\hline SIMD 3 & 46,416 & - \\
\hline SIMD 4 &
\end{tabular}

Table 1: Characteristics of ED attendances in Scotland from January 2015 to September 2018 $(n=5,596,642)$ and the status of four-hour ED target. IQR = Interquartile Range, SIMD = Scottish Index of Multiple Deprivation.

Figure 1 illustrates an increasing proportion of attendances breaching the 4-hour target as age

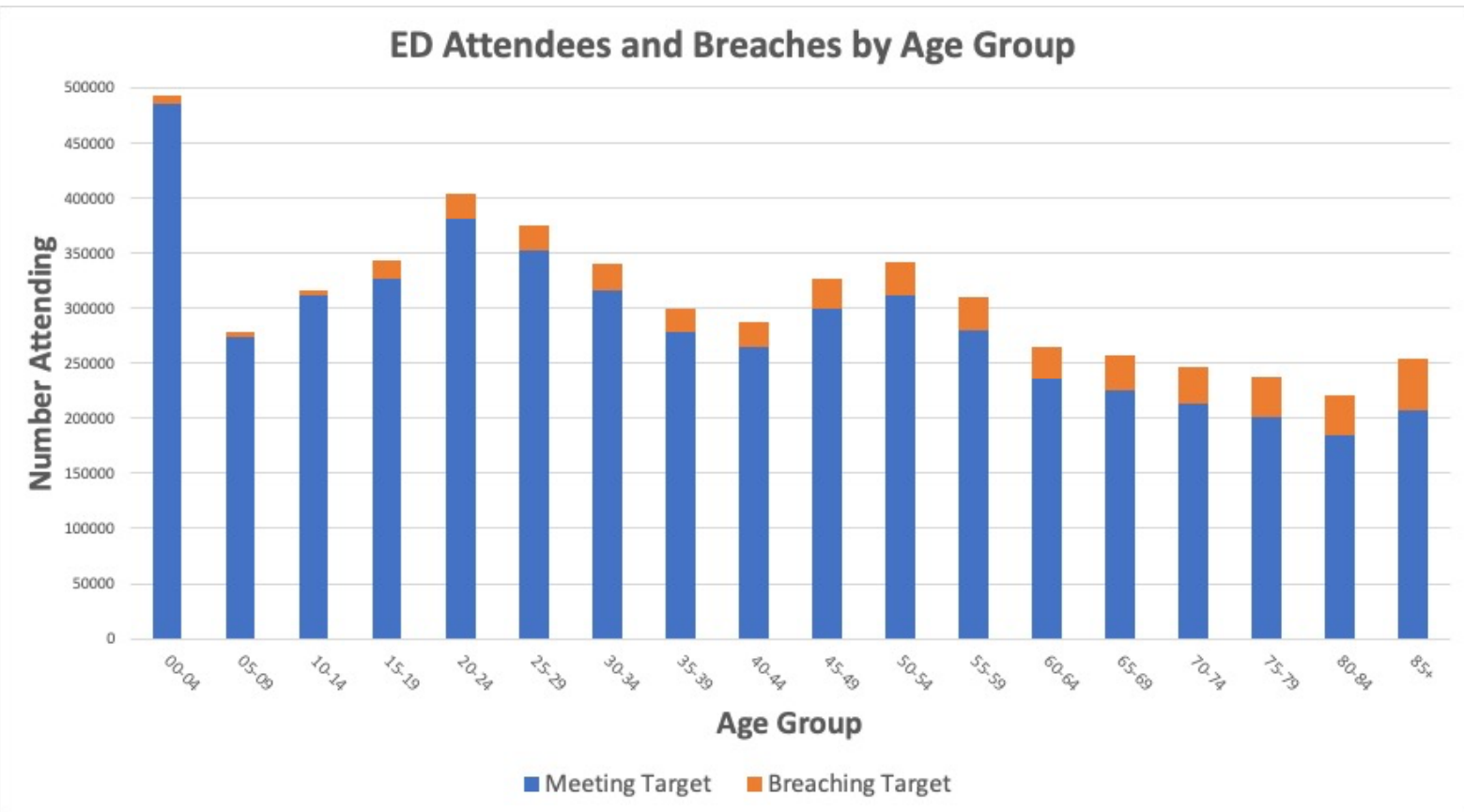

Figure 1: Number of ED attendees split by age and number breaching 4-hour target time within each age category.

The likelihood of breaching the 4-hour target, compared to the 20-24 year age category, 


\begin{tabular}{|c|c|c|c|}
\hline Age Group (Years) & $\begin{array}{c}\text { Percentage } \\
\text { Admitted or } \\
\text { Discharged } \\
\text { Within } 4 \text { Hours }\end{array}$ & $\begin{array}{c}\text { Odds Ratio (95\% CI) of breaching } \\
\text { 4-hour target, compared to } 20-24 \\
\text { year age category }\end{array}$ & $\begin{array}{c}\mathbf{p} \\
\text { Value }\end{array}$ \\
\hline 00-04 & 98.25 & $0.30(0.29-0.31)$ & \multirow{18}{*}{$<0.001$} \\
\hline $05-09$ & 98.53 & $0.25(0.25-0.26)$ & \\
\hline $10-14$ & 98.29 & $0.30(0.29-0.31)$ & \\
\hline $15-19$ & 95.23 & $0.85(0.83-0.87)$ & \\
\hline $20-24$ & 94.44 & 1.00 & \\
\hline $25-29$ & 93.93 & $1.10(1.08-1.12)$ & \\
\hline $30-34$ & 93.21 & $1.24(1.21-1.26)$ & \\
\hline $35-39$ & 92.65 & $1.35(1.32-1.37)$ & \\
\hline $40-44$ & 91.99 & $1.48(1.45-1.51)$ & \\
\hline $45-49$ & 91.63 & $1.55(1.52-1.58)$ & \\
\hline $50-54$ & 90.99 & $1.68(1.65-1.71)$ & \\
\hline $55-59$ & 90.26 & $1.83(1.80-1.87)$ & \\
\hline $60-64$ & 89.12 & $2.07(2.04-2.11)$ & \\
\hline $65-69$ & 87.73 & $2.38(2.33-2.42)$ & \\
\hline $70-74$ & 86.29 & $2.70(2.65-2.75)$ & \\
\hline $75-79$ & 84.92 & $3.02(2.96-3.07)$ & \\
\hline $80-84$ & 83.42 & $3.37(3.32-3.43)$ & \\
\hline $85+$ & 81.73 & $3.80(3.73-3.86)$ & \\
\hline Gender & $\begin{array}{c}\text { Percentage } \\
\text { Admitted or } \\
\text { Discharged } \\
\text { Within } 4 \text { Hours }\end{array}$ & $\begin{array}{l}\text { Odds Ratio ( } 95 \% \text { CI) of breaching } \\
\text { 4-hour target compared to females }\end{array}$ & \\
\hline Female & 91.50 & 1.00 & \multirow{2}{*}{0.007} \\
\hline Male & 92.43 & $0.98(0.98-0.99)$ & \\
\hline SIMD & $\begin{array}{c}\text { Percentage } \\
\text { Admitted or } \\
\text { Discharged } \\
\text { Within } 4 \text { Hours } \\
\end{array}$ & $\begin{array}{c}\text { Odds Ratio (95\% CI) of breaching } \\
\text { 4-hour target compared to SIMD } \\
\text { category } 1\end{array}$ & \\
\hline SIMD 1 & 91.51 & 1.00 & \multirow{5}{*}{$<0.001$} \\
\hline SIMD 2 & 92.14 & $0.92(0.91-0.93)$ & \\
\hline SIMD 3 & 92.94 & $0.82(0.81-0.83)$ & \\
\hline SIMD 4 & 93.37 & $0.77(0.76-0.77)$ & \\
\hline SIMD 5 & 93.20 & $0.79(0.78-0.79)$ & \\
\hline
\end{tabular}

149 Table 2: Odds of breaching 4-hour target for each age group compared to 20-24 years age

150 group, odds of breaching for males compared to females and odds of breaching for SIMD categories 2-5 compared to SIMD category 1 . Odds ratios, confidence intervals and p values calculated using univariable logistic regression models, with breaching the 4-hour target as the outcome and age, gender and SIMD category as predictor variables. CI $=$ Confidence Interval, SIMD $=$ Scottish Index of Multiple Deprivation. 
hour and 12 hour times to admission/discharge (data not shown). The percentage of patients admitted increased linearly with age from $20-24$ years (12.45\% admitted) upwards to the $85+$

When considering major incidents, the $85+$ age group again had the highest odds of breaching (OR 2.05, 95\% CI $2.01-2.09, \mathrm{p}<0.001$ ) compared to the 20-24 years age group. The same was true of minor incidents (OR 2.85, 95\% CI $2.73-2.98, \mathrm{p}<0.001$ ) (data not shown).

Males were slightly less likely to breach the target compared to females (OR 0.98, 95\% CI $0.98-0.99, \mathrm{p}=0.007)$.

Odds ratios for 4 hour breaches compared to SIMD 1 category were 0.92 (95\% CI 0.91 0.93), 0.82 (0.81 - 0.83), 0.77 (0.76-0.77), and 0.79 (0.78-0.79) for SIMD 2, 3, 4, and 5, respectively. In general, breach probability decreased with less deprivation.

\section{Discussion}

Our analysis shows a patient is more likely to stay longer in the ED the older they are. All age groups from 20 years upwards did not meet the national target of $95 \%$, and the percentage of patients waiting longer than four hours increased with age. This is important and relevant to health services since ED waiting time to admission/discharge is often used as a hospital performance indicator.

Our results corroborate those found in a French Study, which showed age greater than 75 years to be associated with increased odds of breaching waiting time within the Paris metropolitan area [9]. However, they go against the results of a study of a Chinese University hospital, which showed age greater than 70 years to be associated with higher odds of time from registration to initial diagnosis being within the target time [10]. The main difference of our study is the scale, with over 5.5 million ED attendances over approximately four years used, whereas other studies have used less than half a million attendances [8], [9], [10]. Our study covered all of Scotland, whereas most previous studies concentrated on either a single hospital [8], [10] or region [9]. Large data by Mason et al [11], which included 15 NHS trusts within England, has previously shown over $65 \mathrm{~s}$ were more likely to breach target than those under 65 .

The lack of other data in our analyses, such as a lack of a measure of disease severity, time to see physician and number of investigations each patient received in the ED is a recognised limitation of our study. Unfortunately, these data and other potential confounders are not available in public domain from ISD Scotland. Perhaps the most significant limitation of our study is the lack of information on the patients disposition decision, namely if they were admitted or discharged. The percentage of patients admitted increased with age, which could account for a significant part of the relationship between age and time to admission/discharge. However, the lack of individual level data including admission status precluded the ability to perform a multivariable analysis by admission status. Future studies should address this limitation by comprehensive data collection, perhaps in a representative sample, to further explore the findings of the current study.

As age increases, the likelihood of multiple comorbidities, functional deficits, sensory impairment or dependence also increases. Older patients are more likely to present severely 
ill, shown by the greater proportion of majors presentations, and they are more likely to be admitted. This makes them more complex to assess and requires a more multidisciplinary approach, which has been shown to increase time within the department [12]. A patient with multiple comorbidities may also require more initial investigations and more discharge planning. This could provide an explanation as to why likelihood of breaching the 4-hour target increases with patient age. The higher likelihood of admission for older patients highlights the systemic challenge of hospital bed availability and its impact on downstream EDs. The findings may be related to issues specific to older patients such as more complex work-ups, greater requirement for discharge planning, greater chance of admission or some combination of all of these factors. Therefore, from the observation of the higher likelihood of breaching, we cannot make the inference that older patients are not receiving adequate care in EDs. The findings are however suggestive of the possibility of poorer outcomes in older patients.

Our findings raise important health service delivery questions regarding older patients in emergency care settings. Whilst there have been suggestions that measures such as 'Frailty units' would take pressure off emergency departments [13], their clinical and cost effectiveness should be assessed properly prior to making recommendations of such health care delivery systems pan-NHS. Greater collaboration between ED staff and multidisciplinary geriatric medicine input at the front door could be a potential solution to ensure older patients receive optimal care.

Our data does not necessarily evidence poor clinical care, since no clinical outcomes were analysed. Nevertheless, our data still shows "a health system ill-equipped to cope with the needs of an aging population with increasingly complex clinical, care and support needs" [14]. This therefore necessitates exploration of hospital and wider system configuration and ED processes to meet the needs of older adults [15].

\section{Conclusions}

Older age is associated with a higher probability of breaching waiting time targets in a linear fashion within NHS Scotland, which is consistent with previous single hospital or regional studies across the globe. This association may be due to the higher proportion of elderly patients being admitted or a more systemic issue, but regardless, the elderly are being put more at risk and services need to address this. 
We gratefully acknowledge the Information Service Division which provided data for this work. This work is carried out as part of Scottish Care of Older People (SCoOP) National Audit Programme, an initiative set up in late 2016 by three key stakeholder organisations, Healthcare Improvement Scotland, the British Geriatrics Society Scotland Council and the University of Aberdeen. We thank the steering group of SCoOP. We also thank the Leslie Wilson Scholarship from NHS Grampian Department of Medicine for the Elderly for the support during this work. In addition, we thank Katherine McGregor of ISD Scotland for her help in obtaining admittance statistics.

\section{References}

1. National Audit Office, Reducing Emergency Admissions [Internet]. $2^{\text {nd }}$ March 2018 [Cited $9^{\text {th }}$ July 2019]. Available from https://www.nao.org.uk/wp-content/uploads/2018/02/Reducing-emergencyadmissions-Summary.pdf

2. Alex Bate, House of Commons Library. Delayed transfers of care in the NHS, Briefing Paper Number 7415. [Internet] $20^{\text {th }}$ June 2017 [Cited $9^{\text {th }}$ July 2019]. Available at https://researchbriefings.parliament.uk/ResearchBriefing/Summary/CBP-7415

3. Taylor C, Benger JR. Patient satisfaction in emergency medicine. Emergency medicine journal. 2004 Sep 1;21(5):528-32.

4. Guttmann A, Schull MJ, Vermeulen MJ, Stukel TA. Association between waiting times and short term mortality and hospital admission after departure from emergency department: population based cohort study from Ontario, Canada. BMJ. 2011 Jun 1;342:d2983

5. Diercks DB, Roe MT, Chen AY, Peacock WF, Kirk JD, Pollack Jr CV, Gibler WB, Smith Jr SC, Ohman M, Peterson ED. Prolonged emergency department stays of non-ST-segment-elevation myocardial infarction patients are associated with worse adherence to the American College of Cardiology/American Heart Association guidelines for management and increased adverse events. Annals of Emergency Medicine. 2007 Nov 1;50(5):489-96.

6. Richardson DB. Increase in patient mortality at 10 days associated with emergency department overcrowding. Medical Journal of Australia. 2006 Mar;184(5):213-6.

7. Scottish Government, Accident and Emergency Waiting Times [Internet]. $2^{\text {nd }}$ July 2019 [Cited $9^{\text {th }}$ July 2019]. Available from

https://www2.gov.scot/About/Performance/scotPerforms/NHSScotlandperformance/AE-LDP

8. Royal College of Emergency Medicine, Emergency Medicine Briefing: Making the Case for the FourHour Standard [Internet]. September 2018 [Cited 30 $0^{\text {th }}$ March 2020]. Available from https://www.rcem.ac.uk/docs/Policy/Making\%20the\%20Case\%20for\%20the\%20Four\%20Hour\%20St andard.pdf

9. Freund Y, Vincent-Cassy C, Bloom B, Riou B, Ray P, APHP Emergency Database Study Group. Association between age older than 75 years and exceeded target waiting times in the emergency department: a multicenter cross-sectional survey in the Paris metropolitan area, France. Annals of Emergency Medicine. 2013 Nov 1;62(5):449-56. 
10. Pan W, Wu M, Ye Z, Qiao X, Zhang K. Effect of age on waiting time of emergency patients: a retrospective analysis of 219299 patients in consecutive 2 years. Zhonghua Wei Zhong Bing Ji Jiu Yi Xue. 2018 Sep;30(9):894-9.

11. Mason S, Weber EJ, Coster J, Freeman J, Locker T. Time patients spend in the emergency department: England's 4-hour rule - a case of hitting the target but missing the point?. Annals of emergency medicine. 2012 May 1;59(5):341-9.

12. Casalino E, Wargon M, Peroziello A, Choquet C, Leroy C, Beaune S, Pereira L, Bernard J, Buzzi JC. Predictive factors for longer length of stay in an emergency department: a prospective multicentre study evaluating the impact of age, patient's clinical acuity and complexity, and care pathways. Emergency Medicine Journal. 2014 May 1;31(5):361-8.

13. Limb M. "Frailty units" would help take pressure off emergency departments, say specialists. Vol. 346, BMJ (Clinical research ed.). 2013.

14. Future Hospital Commission. Future hospital: caring for medical patients. A report from the Future Hospital Commission to the Royal College of Physicians. London: Royal College of Physicians, 2013.

15. Latham LP, Ackroyd-Stolarz S. Emergency department utilization by older adults: a descriptive study. Canadian Geriatrics Journal. 2014 Dec;17(4):118

Ethics approval: Not applicable.

This research received no specific grant from any funding agency in the public, commercial or not-for-profit sectors.

Competing interest: None declared.

Contributions: GE and PM conceived the study. SB provided the data for the study. JQ drafted the initial version along with statistical analysis. All authors then subsequently contributed numerous revisions to the final manuscript. GE is responsible for the overall content of the manuscript. 